to roll

to crease

to fold

to store

to bend

to shorten

to twist

to dapple

to crumple

to shave

to tear

to chip

to split

to cut

to sever

to drop

to remove

to simplify

to differ

to disarrange

to open

to mix

to splash

to knot

to spill

to droop

to flow

to curve

to lift

to inlay

to impress

to fire

to flood

to smear

to rotate

to swirl to support

to hook

to suspend

to spread

to hang

to collect

of tension

of gravity

of entropy

of nature

of grouping

of layering

of felting

to grasp

to tighten

to bundle

to heap

to gather

to scatter

to arrange

to repair

to discard

to pair

to distribute

to surfeit

to compliment

to enclose

to surround

to encircle

to hide

to cover

to wrap

to dig

to tie

to combine

to weave to join

to match

to laminate

to bond

to hinge

to mark

to expand

to dilute

to light

to modulate

to distill

of waves

of electromagnetic

of inertia

of ionisation

of polarisation

of refraction

of simultaniety,

of reflection

of equilibrium

of symmetry

of friction

to stretch

to bounce

to erase

to spray

to systematise

to refer

to force

of mapping

of location

of context

of time

of carbonisation

to contiue

C Richard Serra 1968-69 


\section{Um debate americano: mediação, escultura e arquitetura - sobre a entrevista de Peter Eisenman a Richard Serra em 1983'}

\section{Rafael Urano Frajndlich}

palavras-chave: arquitetura norteamericana;

Richard Serra;

Peter Eisenman; arte norte-americana;

história da arte

keywords: north american architecture; Richard Serra;

Peter Eisenman; north american art; history of art
O artigo analisa uma entrevista do artista Richard Serra feita por seu conterrâneo, o arquiteto Peter Eisenman, em 1983. Ambos já tinham prestígio em suas áreas, o que resultou em um embate de ideias bem fundamentadas e francamente divergentes, cujas colateralidades procuraremos investigar. Destacam-se da entrevista as suas discussões centrais: parte-se das diferentes noções que os artistas possuem acerca das origens da escultura modernista, passando pelas considerações sobre alusão na escultura e arquitetura americanas, desdobrando-se finalmente em distintas posições dos autores acerca do método de produção de suas obras e suas relações com o sítio. Ademais, analisa-se a entrevista na sua contribuição ao debate geral dos artistas nos anos oitenta, e em seus auspícios quanto às fronteiras entre escultura e arquitetura.

This article concerns an interview with the North American artist Richard Serra (1939-) conducted by Peter Eisenman (North American architect, 1932-) in 1983. Both artists were already prestigious in their areas, and that resulted in a deep and diverging debate, whose aspects will be investigated. This article starts with a study of the main issues of the interview: the different notions each artist had embracing the concept of modern sculpture, the question of allusion in sculpture and architecture, their divergences on their ways of developing their work, and how they interact with the site. Moreover, this interview was interpreted in its contribution to the overall discussion on art and architecture, and in its auspice on the borderline between sculpture and architecture. 
1. Este artigo é o desdobramento de um seminário desenvolvido na Faculdade de Arquitetura e Urbanismo da Universidade de São Paulo para a disciplina “Modos de produção do espaço na Arte Contemporânea", do Professor Dr. Agnaldo Aricê Farias, elaborado em conjunto com Mariana Guardani e Patrícia Osses.

2. SERRA, Richard. Notes from Sight Point Road. Perspecta, Nova lorque, The MIT Press, v. 19, 1982, p. 174.
No início dos anos oitenta, Peter Eisenman conduziu uma entrevista com Richard Serra acerca de seu modo de fazer escultura. O encontro dos dois foi fruto de uma série de entrevistas realizada pelo arquiteto para a revista nova-iorquina Skyline: a conversa com Serra foi publicada após entrevistas com os arquitetos Philip Johnson, Leon Krier e Robert Venturi, o escritor Tom Wolfe, dentre outros intelectuais. $\mathrm{O}$ debate entre o escultor e o arquiteto tem ares de casualidade jornalística: mesmo aquele que conheça a fundo a obra dos dois poderia ter dificuldades em ver nelas qualquer interlocução. Essa inadequação não se dá em termos banais (como a inviabilidade de um artista de trabalhar com o outro), ao contrário, a ausência de interlocução se mostra nos próprios dilemas e nas inquietações às quais os autores decidiram se lançar. Peter Eisenman já era uma referência intelectual no campo da arquitetura: fora bem sucedido em lançar o debate da desconstrução no processo de projeto de arquitetura, desdobrando o rigor programático funcional que o movimento moderno havia deixado como legado. Tal debate, para o arquiteto, nunca se limitou ao campo estrito de sua rotina em escritório de arquitetura - na verdade seu estúdio efetivamente só havia se profissionalizado três anos antes, em 1980. Eisenman já era respeitado professor, diretor do Institute for Architecture and Urban Studies e editor-chefe de sua revista, Oppositions.

Serra já era também um renomado escultor: tinha consagração nos Estados Unidos e na Europa desde 1969 (data de suas primeiras exposições individuais, em Nova Iorque e Milão). Na ocasião da entrevista, era recente a inauguração de sua peça urbana "Sight point", onde se confirmava seu processo criativo que via a obra como forma em si inalienável de sua posição no espaço: "o sítio”, escreveu Serra, "determina como eu penso sobre o que vou construir, seja ele urbano ou em campo aberto, uma sala ou outro invólucro arquitetônico”2.

Enquanto o arquiteto se ocupava de uma longa deambulação teórica e introspectiva nas entranhas de um histórico processo arquitetônico de projeto, o escultor se lançava à exploração dos limites da obra de arte diante do sítio que a abriga, de modo a transformar sua percepção espacial de maneira profunda.

Concepções tão distintas acerca da arte, reforçadas por um momento histórico em que a comunidade artística americana via com profundo ceticismo as operações simbolistas, irônicas e descontextualizadas de arquitetos como Charles Moore e Robert Venturi, resultaram em uma entrevista tempestuosa, na qual os artistas se atacaram do começo ao fim, divergindo sobre metodologia, função e autonomia da arte. Apesar de todos esses fatores colaborarem para um estranhamen- 
3. EISENMAN, Peter \& SERRA, Richard. Interview. In: SERRA, Richard. Writings, Interviews. Chicago: University of Chicago Press, 1994. p.141 lesta entrevista foi originalmente publicada na revista Skyline, Nova lorque, p. 14-17. abr, 1983).

4. Ibidem, p. 141 to inicial entre os dois, a resultante é uma entrevista reveladora acerca de aspectos obscuros de suas obras. Partindo da ideia de que para se compreender um autor é preciso suspender seus postulados e colocálos em um ambiente inóspito para lhes verificar sua força e validez, esse breve encontro revela-se um momento excelente para o estudo dos dois artistas americanos.

Eisenman inicia questionando Serra a respeito da representação em sua obra. "A escultura modernista", disse Eisenman, "quebra com a representação em termos de figuração: qualquer representação supostamente passa a representar a escultura em si mesma. Você diz que tenta trazer à tona as intenções esculturais. É essa a representação das intenções esculturais?”3. Poder-se-ia supor que seria uma forma amigável do arquiteto iniciar o debate por uma questão consensual, simples: o rompimento com a representação figurativa, legado das vanguardas do princípio do século XX, que certamente esteve presente na obra de Richard Serra, e que serviria como um ponto de partida para a entrevista antes de entrar em assuntos mais polêmicos. A resposta do escultor, no entanto, já foge dos termos nos quais o arquiteto comportou sua pergunta: "a grande quebra na história da escultura no século XX foi a remoção do pedestal. O conceito histórico de colocar uma escultura no pedestal separava o objeto do espaço a que pertencia o observador"4.

A escolha do arquiteto em começar sua abordagem pela herança vanguardista de rompimento com a figuração é solapada por Serra que considera este traço do modernismo menos importante frente a outro, menos ligado à questão da representação: o abandono do pedestal. Muito mais importante do que o rompimento da temática, da representação, do figurativismo, o abandono de um elemento que servia de interface entre o público e a obra foi a grande conquista das vanguardas. A aproximação da obra do observador, do cotidiano, abriu mais portas, conforme Serra, do que o próprio rompimento da representação.

Ademais, Serra aproveita essa mudança de foco na discussão acerca do legado modernista para efetivamente atacar os arquitetos americanos: "a necessidade que arquitetos têm de revisar a história da escultura desde Rodin é baseada no seu desejo de representar questionáveis valores simbólicos sob o rótulo de um questionável humanismo”. Serra aponta para a recuperação de apliques à arquitetura que remeteriam de forma literal a um contexto que não é aquele onde a obra se insere. "Valores simbólicos se tornaram anúncios: ver Michael Grave Portland Building e Johsnon/ Burgee - AT\&T Building. [...]. Exploração e estratégia de marketing se protegem sob o selo do populismo - Ver 
5. Ibidem, p. 141 et seq.

6. GANDELSONAS, Mario. Linguistics in Architecture. Casabella, n³74, 1973, p. 22.
Charles Moore - Piazza D'Italia, em Nova Orleans”. Serra afirma: "arquitetos são extremamente reacionários em sua adaptação de convenções artísticas diluídas. Seu contínuo uso da arte como ornamentação, decoração, nega as invenções do passado". Arremata: "assim que a arte é forçada ou persuadida a servir valores alheios ela cessa de servir a si mesma. Privar a arte de sua inutilidade é fazer outra coisa que arte" É possível questionar se a acusação direta contra a frivolidade da arquitetura pós-moderna americana feita pelo escultor, diante de Peter Eisenman, não é precipitada. Eisenman era um arquiteto avesso a tais simbolismos: desde o começo da carreira suas investigações foram feitas no sentido oposto àquele do símbolo e da significação. Ao tentar impor uma diferenciação entre sua prática e a dos arquitetos, Serra expõe como Eisenman tem consonância com ele no que concerne à questão da representação na arte. Mario Gandelsonas ao escrever sobre o arquiteto nova-iorquino ressalta que "um dos mais interessantes e originais aspectos do trabalho de Eisenman é a descoberta da possibilidade de modificações dentro da arquitetura, que é resultado de uma virada na característica dominante da arquitetura da semântica para a sintática”.

Remontando à carreira do arquiteto até 1983, podemos ver que Eisenman explorou ao máximo procedimentos de projeto e articulações do vocabulário da arquitetura (o pilar, a viga, até decantar no plano, no ponto, nas linhas...), privilegiando-os até a arquitetura não poder significar nem remeter a nada mais senão às suas estruturas internas. Eisenman, como Serra, busca as entranhas de sua prática a ponto de colocar em risco a própria utilidade de seus projetos: bastaria para isso um breve itinerário por sua série de residências ("House I" até a "House El Even Odd"), nas quais diversas técnicas e procedimentos projetuais são operados até o alcance de diferentes resultados que polemizam a respeito dos significados históricos da casa (as relações entre áreas íntimas e áreas de uso comum, as diferenças no trato das dimensões para cada ambiente etc.), menos por uma preocupação do arquiteto em relação a esta semântica do que com o efeito colateral da exaustiva operação sintática.

Essa posição de Eisenman no meio da arquitetura, como uma avis rara dentro do dito pós-modernismo americano, é justamente a alavanca que ele utiliza para absorver a primeira fala de Serra como consenso: ambos entendem a arte como algo distante do jogo de alusões que Johnson, Venturi e Charles Moore, em diferentes graus, faziam uso.

Com efeito, continuará insistindo no tom da possível alusão que a obra faz a algo externo a ela - mesmo diante de um artista extremamente rigoroso com os processos internos de seu trabalho, como 
9. Ibidem, p. 145.

10. EISENMAN ARCHITECTS, "Office profile", disponível em www.eisenman architects.com.

Richar Serra, modelo para o "Memorial do Hocausto".

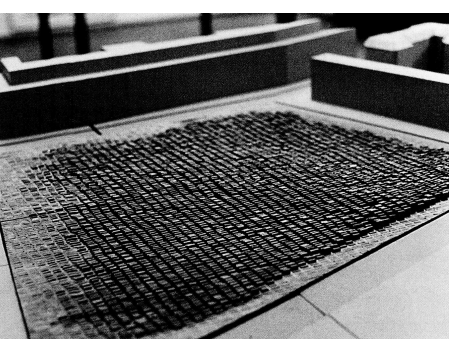

equivaler a qualquer outra coisa que não tenha peso e se sustente deste modo: como cartas do baralho. Não se trata, segundo o escultor, de uma alusão, mas de uma equiparação através de um procedimento construtivo, concreto, para subsumir o peso, a força da gravidade, para conceber outra noção espacial: "uso a gravidade como princípio construtivo. Não estou particularmente interessado em desequilíbrio"9.

Trata-se de uma forma que busca demonstrar um princípio construtivo: o uso das chapas metálicas por Serra resulta numa exposição didática do equilíbrio de forças. O debate sobre a não figuração é levado ao extremo pelos dois artistas, a ponto da própria possibilidade de colapso o representar. Essa tensão é talvez aquilo que a relação entre Eisenman e Serra teve de mais marcante. Anos depois dessa entrevista, não podemos esquecer de outro breve episódio em que essa questão ressurge: a associação de Eisenman e Serra para fazer o "Memorial dos judeus assassinados no Holocausto”, em Berlim. Em 1998, os desenhos iniciais dos volumes de concreto armado, formando um enorme e mudo jardim no coração da capital alemã, foi fruto de criação conjunta dos dois artistas. Serra abre mão do projeto logo nas primeiras reuniões, por não estar disposto a fazer concessões à obra por fatores políticos (a saber: a redução do número de peças pela metade, a pavimentação do entorno do memorial e a redução da altura máxima dos blocos de concreto), e formais - que reverberam melhor os temas da entrevista decorrentes das pedras, menores em seu tamanho, deixarem de ser volumes em si e passarem a aludir a lápides, e pior, a emular em seu conjunto um cemitério judaico na Polônia. Eisenman, por outro lado, permaneceu no projeto e o construiu.

Em 1983, já se delineava essa diferença entre a maneira como os dois autores romperiam com a representação em suas obras: Eisenman não capitularia a motivos imediatos, apliques literais, mas estaria disposto, através de seu modo de operar, a entrar em contato com a carga simbólica que eventualmente se poderia ter como resultante de suas operações sintáticas - que eventualmente revelam cargas que podem, efetivamente, significar algo. O texto de apresentação de seu escritório na internet diz que "considera as camadas arqueológicas, artísticas e culturais em cada sítio, não apenas os óbvios contextos e programas de um prédio" para "produzir formas singulares e intrigantes imbuídas com um único sentido de lugar" ${ }^{\prime 10}$. Confirma na apresentação as próprias justificativas para as transformações que as operações sintáticas no princípio dos anos 1970 de Eisenman - "House I", "House II", "House III" - terminassem por abarcar em sua metodologia, pouco a pouco algumas variáveis semânticas. Eisenman, sobre sua "House X", em Michigan, considera que 
11. EISENMAN, Peter. House X. Nova lorque: Rizzoli, 1982, p. 34

12. SERRA, Richard. Notes from Sight

Point Road. In: op. cit., p. 178

13. EISENMAN, Peter. Diagram Diaries. Londres: Thames \& Hudson, 1999, p. 238. "é fortemente matizada por ideias metafóricas de ruína, decadência e despedaçamento, mas busca usar essas ideias de uma maneira totalmente diferente dos pós-modernistas. Enquanto a imagética do pós-modernismo contém uma velada antipatia em relação a qualquer coisa ideológica, a imagética da 'House X' é baseada em uma explícita preocupação ideológica com uma condição cultural, a saber: a aparente inabilidade do homem moderno em sustentar uma crença em sua própria racionalidade e perfeição" ${ }^{11}$.

Eisenman parte da sintaxe, mas não renega sua obra se o ponto de chegada for alguma nova manifestação semântica. Serra, por outro lado, imediatamente desconsidera qualquer possibilidade de que sua obra possa ser utilizada para alguma outra coisa que não a nova percepção do lugar em que se insere. Ao escrever sobre sua obra, surge o seguinte postulado como fato central: "creio que se a escultura tem qualquer potencial é aquele de criar seu próprio lugar e espaço, e trabalhar em contradição com estes lugares e espaços onde foi criada" ${ }^{12}$.

Criação do próprio lugar no espaço como oposição a operações formais que resultem na exposição de novos significados do lugar. A antítese entre os dois artistas começou como uma discussão acadêmica: quais postulados das vanguardas ainda apareceriam como predominantes em seus trabalhos; e pouco a pouco revelou uma tensão acerca de suas metodologias de leitura do lugar. Partindo dos denominadores comuns, parece claro que ambos recusam abordagens apriorísticas de suas obras: elas surgem de procedimentos e variáveis que moldam a obra, sem uma teleologia acerca de seu ponto de chegada. Se remontarmos a materiais e esboços de Serra, encontraremos uma lista escrita a mão, elencando todos os procedimentos possíveis para se fazer a uma peça metálica. Dentre elas: "to bend, to shorten, to turst...”. Ele afirmou: "o que era muito, muito importante para mim era lidar com a natureza do processo. Então eu escrevi esta lista de verbos".

De modo semelhante, ao publicar seu itinerário metodológico Diagram Diaries, Peter Eisenman também lista, em uma das várias tabelas estatísticas avaliando seu trabalho, diversos procedimentos formais possíveis de se aplicar a um edifício, como "shifting, twisting, morphing, nesting..." "13. É possível contestar contra as diferenças existentes entre um pequeno documento escrito a mão, anterior à obra, e uma planilha bem organizada que articula diversos projetos para ter uma melhor visão do todo. Mas para a argumentação que se tece, tais documentos bastam como testemunho de uma maneira de se abordar a obra 
14. Ibidem, p.35.

15. SERRA, Richard. Notes from Sight Point Road. In: op. cit., p. 173.

Peter Eisenman, “Biocentrum", maquete.

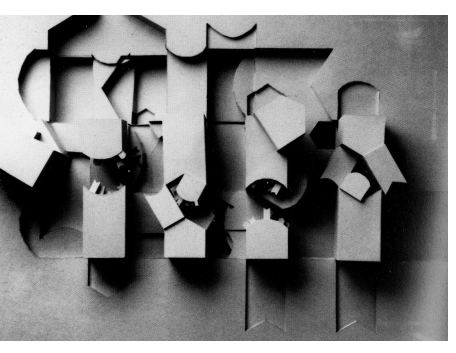

privilegiando o seu método de confecção. Nisto, Serra e Eisenman pensam de maneira extremamente similar. As diferenças que surgirão, serão em parte, por diferenças pessoais em suas linhas artísticas, em parte, pela própria natureza diferente entre a arquitetura e escultura.

Eisenman parte desta lista de ações e as coloca em articulação em um ambiente abstrato, onde as diversas variáveis específicas do lugar onde o projeto vai se inserir são consideradas: antes do projeto, aquele jogo de desenhos que permite a orientação dos construtores de modo a executar com fidelidade a obra, Eisenman concebe o ambiente suspenso chamado "diagrama".

O diagrama, segundo Eisenman, "atua como agência da relação entre um sujeito autoral, um objeto arquitetônico e um sujeito receptor" ${ }^{14}$. Como exemplos claros desse procedimento, o "Biocentrum" em Frankfurt, com seus caminhos levemente sugerindo a hélice que compõe os desenhos esquemáticos de um DNA, somados às exigências programáticas do laboratório e alinhado aos acessos diversos que o centro possui com as ruas da cidade. Ou então, o projeto de habitação social em Berlim, nas proximidades do então Check Point Charlie onde a volumetria dos edifícios compostos remontam ao antigo gabarito e à morfologia do quarteirão, antes da cisão da capital alemã.

Entre seu pensamento e a obra, portanto, Eisenman impõe a esfera objetiva do diagrama - uma peça chave onde seu procedimento rigoroso de decantação sintática pode aos poucos conceber uma inesperada abordagem formal à intervenção requerida. Não se pode ignorar a vontade de sintetizar diversos fatores, históricos ou formais, subjacentes ao local que se investiga. Existe no arquiteto nova-iorquino uma esfera de profunda mediação entre as variáveis do projeto e sua resolução. É preciso que essa esfera, no entanto, seja a mais precisa possível, contenha o máximo de variáveis, considere em sua equação as mais sofisticadas operações.

Serra adota o oposto dessa postura. Suas obras não possuem uma instância de mediação, nem mesmo projetual. Onde em outros artistas (como Gordon Matta-Clark ou Robert Smithson) encontramos esboços e preparações para as intervenções, Serra declara que "as esculturas são resultado de experimentação e invenção. Eu nunca faço desenhos de antemão" ${ }^{15}$. A ausência de esboços, a intervenção direta, alcança o ápice na obra de Serra em seus projetos de interiores em que as peças são decalcadas diretamente nas paredes: "Egyptian Horsemix", "High Verticals", "A New Drawing”, e a obra feita no Brasil dentro do Centro Hélio Oiticica, "Rounded": a leitura do lugar é imediata, está presente na visita do artista ao local, e já deságua na obra. "Rounded", com suas formas circulares distribuídas ao longo dos arcos, conta com esboços 
Peter Eisenman, diagrama do "Biocentrum"
16. EISENMAN, Peter \& SERRA, Richard. Op. cit. p.146.

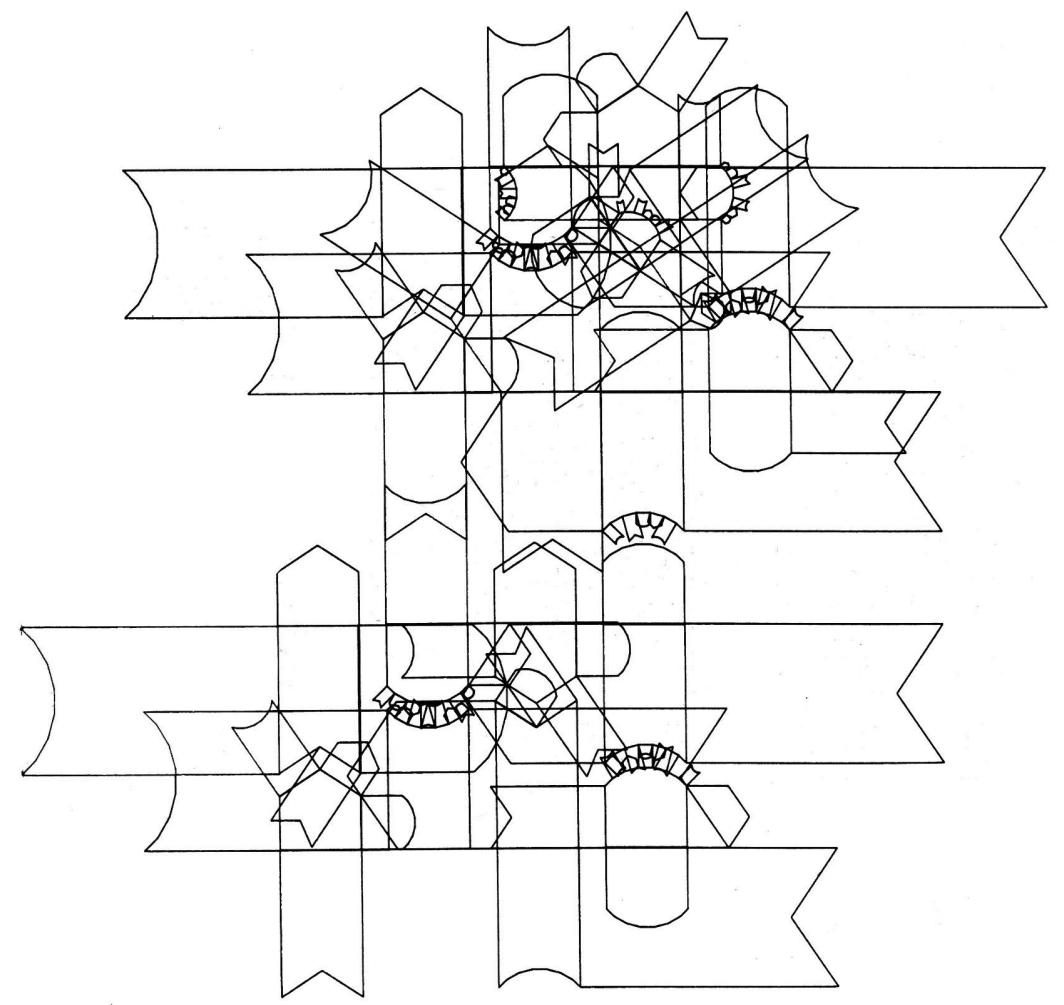

precários, feitos em guardanapos dobrados. Existe uma vontade de transpor o pensamento diretamente para a ação.

Esta "imediatez" ressurge na entrevista, na ocasião em que Peter Eisenman pergunta sobre a influência do pintor americano Jackson Pollock nas peças de Serra, ao que o escultor responde:

As pinturas de Pollock nunca ultrapassam a borda da tela, a passagem da pintura é absolutamente controlada. Pessoas interpretam mal o como do processo e pensam que alguém trabalhando sobre uma tela no chão de uma maneira espontânea deve estar fora de controle. Mas as decisões de quanta pintura usar, onde aplicar, todas as condições formais como linha, massa, camadas, são extremamente organizadas. [...] Se minha origem como pintor culminou em algo, foi em Pollock ${ }^{16}$.

Nessa afiliação, Serra demonstra a ligação direta entre sua atuação direta "na tela" - nas ruas, nos prédios. Mesmo obras com grandes peças metálicas, que exigem planejamento de fabricação e montagem, são resolvidas pelo autor sem grandes mediações. Não será absurdo dizer que a resolução do projeto em Eisenman também envolve o "debruçar-se sobre algo", operar criteriosamente, mas seguindo as nuances do momen- 
17. Ibidem, p. 147.

18. Ibidem, p. 153. to, sobre seu diagrama - mas o diagrama não será a obra. As diferenças dessa operação atingem o ponto mais alto da entrevista, onde as opiniões dos dois artistas se separarão de maneira definitiva.

Eisenman, após a discussão sobre Pollock, insere uma breve discussão sobre arte abstrata e concreta, insistindo nas questões de representação na obra. Até que o ponto de chegada dessas considerações é o "Rotary Arc" de Serra, projeto inserido em uma praça pública. O diálogo torna-se truncado:

P.E: Estou tentando chegar a uma noção de estrutura como parte da inefável condição de um objeto. A presença da estrutura em si não é garantia de arte. $\mathrm{O}$ que faz a arte além da estrutura?

R.S: Não é algo que programo em meu trabalho, apesar de reconhecê-lo. Não estou interessado em estruturas que definam o contexto em questão.

P.E: Mas você não está interessado na autosseleção antes da sua própria [sic]? Você não faz uma seleção arbitrária, eles selecionam a si mesmos de uma gama de possíveis arqueologias.

R.S: Estou confuso. Eles não se selecionam. Eles são responsabilidade da pessoa que está formulando o problema e tomando decisões sobre a solução. Você sugere que eu esteja lá para somente receber estruturas? [...]

P.E: Você não inventou o "Rotary Arc". Você o encontrou, ele era preexistente.

R.S: Preexistente no mundo? Isso soa extremamente calvinista. P.E: Não, preexistente no contexto e no universo da escultura ${ }^{17}$.

A pesquisa diagramática se sobressai na sua tonalidade arqueológica. Não existe invenção em Eisenman que não seja investigação, exploração, prospecção do lugar e de suas variáveis. O sítio dessa investigação é laboratorial: o diagrama é algo que acontece dentro do campo do estúdio, passa por procedimentos metrificados. O "Rotary Arc" - e qualquer outra obra de arte que se pretenda site specific - é colocado como algo que só surge após longa decantação in vitro. Daí decorre suas considerações sobre arquitetura, que a aproxima de um jogo com regras e posições:

No universo da escultura o próprio conceito sugere a si mesmo. Como um jogo de xadrez: todas as linhas existem potencialmente, mas não são necessariamente vencedoras ou elegantes. Mas o contexto da invenção da poética, a arte de ganhar o jogo, permanece nas regras do jogo em si, no tabuleiro. Temos que encontrá-lo, mas ele se sugere para nós ${ }^{18}$.

A escultura, a metodologia artística em geral, é para Eisenman equiparável a um jogo de xadrez. É algo quase literal, poder-se-á dizer: o esporte do xadrez, eminentemente mental, é pautado por diversas 
Richard Serra, "St. Johns Rotary Arc", $1975 / 80$

19. EISENMAN, Peter \& SERRA, Richard. Op. cit., p.147.

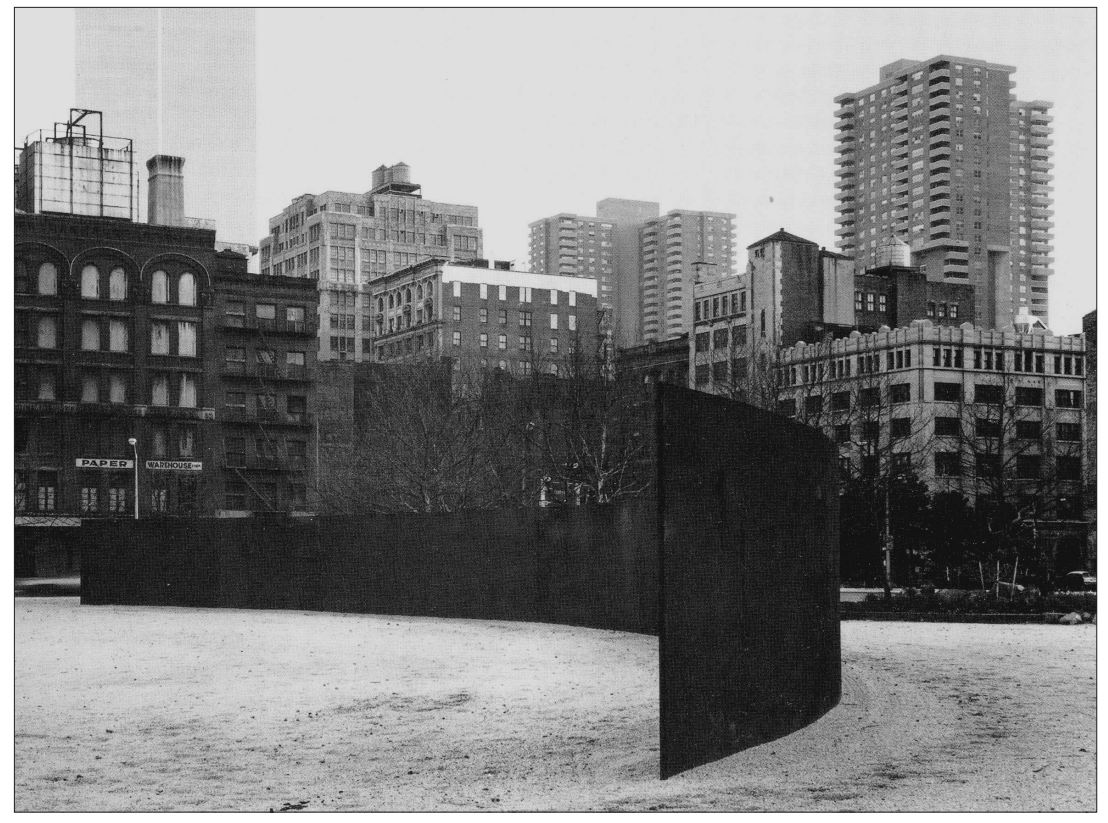

regras justapostas, que se entrelaçam permitindo um sem fim de possibilidades. No entanto, ao longo de seus campeonatos, disputas, jogos históricos e mestres, sempre é possível imprimir em suas variáveis personalidade ao jogo: há maneiras agressivas, defesas, ataques. $\mathrm{O}$ tabuleiro pouco a pouco registra as relações dos jogadores e atesta sua condição e percepção do espaço - do tabuleiro. A leitura da posição das peças resulta em novas posições, até que decantem na forma final do tabuleiro - o xeque-mate. Não se pode ler essa consideração com teor competitivo: a oposição dos jogadores de xadrez é mais uma variável que põe em movimento o diagrama em que o tabuleiro se transforma: diagrama que reflete a maneira de duas pessoas atuarem sobre um espaço. $\mathrm{O}$ que parece à primeira vista limitante é, na verdade, algo amplo: para Eisenman, o diagrama que concebe em seus projetos é análogo ao tabuleiro de xadrez, laboratório onde diversos tipos de relação se encontram e disputam (portanto se justapõem e se movimentam) até solidariamente chegarem à obra.

A resposta de Serra, naturalmente, vai na contramão desta abstração: "não há regras. [...] Um método que uso é uma caixa de areia enorme onde trabalho soluções construtivas. A areia me permite uma prática que não se apóia na teoria” ${ }^{19}$.

A alusão à areia é recorrente em Serra. Em depoimentos acerca de suas primeiras intuições como artista, declara como na sua infância, andando pela praia, chamou-lhe a atenção os registros de suas pegadas 
20. Entrevista de Charlie Rose a Richard Serra (6 e 7 jun. 2007). Disponível em: http://www.charlierose.com/view/interview/8534. na $\operatorname{areia}^{20}$. A areia, superfície composta por pequenos grãos que vão tomar a forma daquilo que a comprime: imediata interação entre o lugar e a ação humana, sincera e rápida atuação. A caixa de areia pode em si ser considerada uma mediação entre o pensamento de Serra e a aplicação de suas grandes peças no seu lugar específico. Mas nada de mental existe nessa mediação. Se deixarmos de lado a literalidade do imediato (Pollock realmente é o maior exemplo), podemos ver como a abordagem de Serra é muito mais desprovida de interesse em significações e muito mais rica em estudar com rigor as possibilidades formais com que se pode registrar o sítio. A escultura não decanta já que a areia se apaga com cada nova volta ou dobra da maquete metálica que Serra desenvolve - dela não existe resultante, a areia não normaliza os procedimentos criativos: cabe ao escultor o critério de parar. Assim, seu pensamento mesmo é impresso e reimpresso na areia, e dela, a obra resulta no sítio, específico testemunho de um processo com pouquíssima mediação.

$\approx \approx \approx$

Este breve debate é mais um testemunho de uma época onde a representação, a relação entre contexto e os usos da arte estavam no centro do debate norte-americano - tanto na escultura quanto na arquitetura.

Entretanto, as maneiras como os artistas concebem seus processos criativos - semelhantes em seu ponto de partida, mas radicalmente divergentes nos meandros que levam ao seu ponto de chegada - servem para mostrar como, embora desprovidos de vontade de partir de leituras banais dos terrenos de intervenção e dispostos a atuar de maneira crítica em relação às vanguardas europeias que lhes precederam, existe um vasto terreno de diferença, mesmo quando os dilemas são parecidos. À guisa de conclusão, poder-se-á trazer à tona uma leitura alternativa a essa, personalista, dos dois artistas acerca das diferentes abordagens processuais que a forma da entrevista nos leva a fazer. Sob um prisma mais amplo, é possível supor diferenças radicais entre escultura e arquitetura surgidas desse debate. Serra, pelo lado da invenção, aproveita-se do território de contestação e novas proposições que a escultura que classicamente esteve ao lado das belas artes e da qual não se tecem expectativas prosaicas cotidianas. Das razões levantadas para a remoção do "Tilted Arc", surgiu aquela de que a escultura atrapalhava o fluxo de pedestres que cruzavam a praça. A intervenção é francamente legítima sob o ponto de vista de que não se deve esperar uma utilidade, muito menos uma solidariedade a qualquer utilidade anterior no terreno. A metrópole, que tem sido o locus da arquitetura desde o século XVIII, é 
21. SERRA, Richard. Notes from Sight Point Road. In: op. cit., p. 180. um palco livre para a intervenção artística: uma areia moldável à invenção, à recriação e à subversão de seus procedimentos.

Em posição menos flexível está o arquiteto: seus desejos e aspirações invariavelmente recairão nas expectativas dos ambientes que serão criados e frequentados. Quando Eisenman cria uma casa, como a "House I", não importa a liberdade com que ele trata sua morfologia, a leitura de seus quartos, salas, cozinha serão feitas tomando-se como referencial toda a história das residências. A temática, na arquitetura, não é escolha do artista: ela sempre se pautará pelos espaços em que as pessoas passam os dias - o próprio Serra parodia isso em seu texto: "a diferença entre arquitetura e escultura na paisagem é: uma casa é uma casa é uma casa é uma casa...”21.

Dessa maneira, não há processo em arquitetura que não seja atualização histórica. Eisenman preferiu a abordagem arqueológica, a investigação quase científica de como o lugar se configurou ao longo do tempo, em como os programas que se têm em foco se constituíram, em como as tipologias históricas se ampararam em diferentes soluções geométricas. Somando esses fatores, e os operando à exaustão, o autor consegue estabelecer uma resultante que não tem escolha senão ser colocada no crivo desses interlocutores lançados ao diagrama. Em arquitetura, Serra tinha clareza disto, é impossivel desenhar algo desprovido de significado. Eisenman, apesar de ser talvez o arquiteto pós-moderno mais fiel a tal lema, capitulou diante da contradição. Por essa razão, talvez sua parceria com Richard Serra na Alemanha, em 1998, estava condenada já de início, pois malgrado a admiração do escultor por Louis Kahn, Frank Lloyd Wright - e as semelhanças de dilemas construtivos com Mies Van der Rohe - sua grande preocupação com a forma, como aquela entrevista quinze anos antes já mostrara, era irreconciliável com a prática da arquitetura.

Rafael Urano Frajndlich é arquiteto e aluno de pós-graduação da Faculdade de Arquitetura e Urbanismo da USP, na área de História e Fundamentos da Arquitetura e Urbanismo. Desde 2008, desenvolve pesquisas sobre historiografia de arquitetura, com dissertação de mestrado em andamento sob o título de O Projeto histórico de Manfredo Tafuri: Le Corbusier como protagonista de suas investigações sobre a arquitetura moderna entre $1968 e$ 1980. 